\title{
Nationwide survey of antihypertensive treatment for acute intracerebral hemorrhage in Japan
}

\author{
Masatoshi Koga $^{1}$, Kazunori Toyoda ${ }^{1}$, Masaki Naganuma ${ }^{1}$, Kazuomi Kario ${ }^{2}$, Jyoji Nakagawara ${ }^{3}$, Eisuke Furui ${ }^{4}$, \\ Yoshiaki Shiokawa $^{5}$, Yasuhiro Hasegawa ${ }^{6}$, Satoshi Okuda ${ }^{7}$, Hiroshi Yamagami ${ }^{8}$, Kazumi Kimura9, \\ Yasushi Okada ${ }^{10}$ and Kazuo Minematsu ${ }^{1}$, for the Stroke Acute Management with Urgent Risk-factor \\ Assessment and Improvement (SAMURAI) Study Investigators
}

\begin{abstract}
Acute hypertension is associated with hematoma enlargement and poor clinical outcomes in patients with intracerebral hemorrhage (ICH). However, the method of controlling blood pressure (BP) during the acute phase of ICH remains unknown. The aim of this study is to show current strategies about this issue in Japan. Questionnaires regarding antihypertensive treatment (AHT) strategies were sent to neurosurgeons, neurologists and others responsible for ICH management in 1424 hospitals. Of 600 respondents, $550(92 \%)$ worked at hospitals wherein acute ICH patients are managed and $548(99.6 \%)$ of them agreed with the application of AHT within $24 \mathrm{~h}$ of ICH onset. Most answered that the systolic BP threshold for starting AHT was $180 \mathrm{~mm} \mathrm{Hg}(36 \%)$ or $160 \mathrm{~mm} \mathrm{Hg} \mathrm{(31 \% ),} \mathrm{which} \mathrm{differed} \mathrm{significantly} \mathrm{between} \mathrm{neurosurgeons} \mathrm{(median,} 160 \mathrm{~mm} \mathrm{Hg}$ ) and neurologists/others $(180 \mathrm{~mm} \mathrm{Hg}, P<0.001)$. The goal of lowering systolic BP was to reach a maximum of 140,150 or $160 \mathrm{~mm} \mathrm{Hg}$ according to 448 respondents (82\%) and 209 (38\%) intensively lowered systolic BP to $\leqslant 140 \mathrm{~mm} \mathrm{Hg}$. Nicardipine was the first choice of intravenous drug for $313(57 \%)$ and the second choice for 146 respondents $(27 \%)$. However, 141 $(26 \%)$ thought that nicardipine is inappropriate mainly because of a conflict with a description of contraindications on the official Japanese label for this drug. In conclusion, the present Japanese respondents, especially neurosurgeons, lower BP more aggressively than recommended in domestic and Western guidelines for managing acute ICH patients. Nicardipine was the most frequent choice of antihypertensive agent.
\end{abstract}

Hypertension Research (2009) 32, 759-764; doi:10.1038/hr.2009.93; published online 26 June 2009

Keywords: acute stroke; antihypertensive therapy; intracerebral hemorrhage; web questionnaire

\section{INTRODUCTION}

Intracerebral hemorrhage (ICH) is not only life threatening but also causes major disability. The annual incidence of ICH in Japan is several-fold higher than that in Caucasian populations. ${ }^{1-5}$ Chronic hypertension is a leading risk factor for $\mathrm{ICH}^{2,6,7}$ and such patients often have high blood pressure (BP) on admission. Acute high BP might enhance active intracranial bleeding and hematoma growth, which could be a determinant of poor clinical outcome. ${ }^{8-12}$ In contrast, some investigators insist that high BP might work to maintain normal cerebral blood flow and prevent peri-hematomal ischemic damage. ${ }^{13,14}$ However, pharmacologically mediated BP reduction apparently has no adverse effects on cerebral blood flow in humans or other animals. ${ }^{15,16}$ Control of BP for acute ICH remains controversial.

American Heart Association/American Stroke Association (AHA/ASA) guidelines ${ }^{17}$ and the Japanese Guidelines for the Management of
Stroke $2004^{18}$ both recommend lowering of BP for ICH patients with systolic blood pressure (SBP) of $>180 \mathrm{~mm} \mathrm{Hg}$ or mean arterial pressure of $>130 \mathrm{~mm} \mathrm{Hg}$. The target BP level has not been defined. The European Stroke Initiative (EUSI) advocates an upper recommended limit of 180/105 $\mathrm{mm} \mathrm{Hg}$ and a target BP of $160 / 100 \mathrm{~mm} \mathrm{Hg}$ for acute ICH patients with known earlier hypertension or signs of chronic hypertension. ${ }^{19}$ However, these recommendations are based on limited information and neither their usefulness nor their effects are well established.

Another concern regarding the lowering of BP in acute $\mathrm{ICH}$ patients is of the differences in recommendations for intravenous (i.v.) antihypertensive drugs among guidelines. Both the AHA/ASA and the EUSI guidelines recommend i.v. administration of the adrenergic inhibitors, labetalol and esmolol, and of the calcium channel blocker, nicardipine. In Japan, labetalol is not approved for commercial use, esmolol is used only for antiarrhythmia, and nicardipine

${ }^{1}$ Cerebrovascular Division, Department of Medicine, National Cardiovascular Center, Suita, Japan; ${ }^{2}$ Division of Cardiovascular Medicine, Department of Medicine, School of Medicine, Jichi Medical University, Shimotsuke, Tochigi, Japan; ${ }^{3}$ Department of Neurosurgery and Stroke Center, Nakamura Memorial Hospital, Sapporo, Japan; ${ }^{4}$ Department of Stroke Neurology, Kohnan Hospital, Sendai, Japan; ${ }^{5}$ Department of Neurosurgery, Kyorin University School of Medicine, Mitaka, Japan; ${ }^{6}$ Department of Neurology, St Marianna University School of Medicine, Kawasaki, Japan; ${ }^{7}$ Department of Neurology, National Hospital Organization Nagoya Medical Center, Nagoya, Japan; ${ }^{8}$ Department of Neurology, Stroke Center, Kobe City Medical Center General Hospital, Kobe, Japan; ${ }^{9}$ Department of Stroke Medicine, Kawasaki Medical School, Kurashiki, Japan and ${ }^{10}$ Department of Cerebrovascular Disease, National Hospital Organization Kyushu Medical Center, Fukuoka, Japan

Correspondence: Dr K Toyoda, Cerebrovascular Division, Department of Medicine, National Cardiovascular Center, 5-7-1 Fujishirodai, Suita, Osaka 565-8565, Japan. E-mail: toyoda@hsp.ncvc.go.jp

Received 25 March 2009; revised 13 May 2009; accepted 26 May 2009; published online 26 June 2009 
administration for hyperacute ICH patients is limited by the description on the official label.

To conform to worldwide trends, BP control in ICH patients in Japan should be standardized, domestic recommendations that differ from others should be reconsidered, and an active role in international trials should be taken. Therefore, we conducted a nationwide web survey as the first step toward defining current standard strategies of $\mathrm{BP}$ control in Japanese patients with acute ICH.

\section{METHODS}

We surveyed 1424 certified training institutes recommended by the Japan Stroke Society, the Japan Neurosurgical Society and the Societas Neurologica Japonica. Web questionnaires (https://ssl.e-ult.jp/ICH/, for limited members) regarding acute ICH management and antihypertensive treatment (AHT) strategies were sent to hospital directors in July 2008 with a request that they encourage responsible physicians involved in stroke management to reply by September 2008.

The inquiry started by questioning whether acute ICH patients are usually treated in the respondents' hospitals. Those who responded affirmatively were required to answer seven questions about conditions surrounding acute ICH management and 14 questions about AHT for acute ICH (Table 1). When respondents disagreed with AHT for acute ICH patients in Question 10 (Q10), responses to subsequent questions were not required. All answers were multiple choice, except for Questions 2, 5 and 9, which required integral numbers.

At the end of the survey, we asked if the respondents were interested in further inquiries. Those who answered in the affirmative received a supplementary questionnaire in October 2008 to determine whether their patients experienced side effects of i.v. antihypertensive drugs during acute ICH management. Respondents were only required to e-mail a reply to this simple question if they recognized possible side effects.

\section{Table 1 The web questionnaire in this study}
Conditions for acute $\mathrm{ICH}$ management
Q1. What is your specialty?
Q2. How long is your career in clinical medicine?
Q3. How many acute ICH patients (hospitalized within 7 days of onset) are treated in your hospital per year?
Q4. Who mainly treats acute ICH patients at your hospital?
Q5. How many medical physicians attend patients with acute $\mathrm{ICH}$ at your hospital?
Q6. Where do you treat acute $\mathrm{ICH}$ patients?
Q7. Is your medical staff for acute $\mathrm{ICH}$ available during the nighttime and on weekends?

\section{Antihypertensive therapy (AHT) for acute $\mathrm{ICH}$}

Q8. How do you measure BP in acute $\mathrm{ICH}$ patients?

Q9. How many times do you measure BP during the initial $24 \mathrm{~h}$ ?

Q10. Do you agree with AHT within $24 \mathrm{~h}$ after ICH onset?

Q11. When do you start AHT?

Q12. At which SBP level or more do you initiate AHT?

Q13. At which level or less do you lower SBP during the hyperacute stage?

Q14. Which i.v. antihypertensive agent do you primarily choose?

Q15. Why do you choose the agent in Q14?

Q16. Which is your second choice of i.v. antihypertensive agent?

Q17. Do you think the listed i.v. agent is inappropriate for acute $\mathrm{ICH}$ patients?

Q18. Why do you choose the agent in Q17?

Q19. When do you think active intracranial bleeding ceases?

Q20. Which oral antihypertensive agent do you administer after acute i.v. AHT?

Q21. To which level or less do you lower SBP during the chronic stage?

Abbreviations: $\mathrm{AHT}$, antihypertensive treatment; $\mathrm{BP}$, blood pressure; $\mathrm{ICH}$, intracerebral hemorrhage.

\section{Statistics}

The BP thresholds in Questions 12, 13 and 21 were compared between neurosurgeons and respondents from other specialties using the MannWhitney $U$-test. Categorical variables were compared using the $\chi^{2}$ test. A $P$-value of $<0.05$ was considered to represent a significant difference.

\section{RESULTS}

Among a total of 602 collected responses, two were excluded from the analyses because the same respondents answered twice, leaving 600 responses remaining from 1424 (42.1\%) hospitals. Of these, 50 replied that they did not usually treat patients with acute ICH at their hospitals. Finally, 550 responses $(38.6 \%$ of 1424 hospitals) were analyzed.

\section{Conditions for acute ICH management}

Of the 550 respondents, $457(83.1 \%)$ were neurosurgeons (Q1; Table 2). Overall, the respondents had spent a median of 23 years in clinical medicine $(\mathrm{Q} 2)$. The median number of $\mathrm{ICH}$ patients treated annually ranged between 41 and $60(\mathrm{Q} 3)$. The main department for ICH management was neurosurgery $(79.5 \%)$, whereas $10.5 \%$ of respondents replied that a mixed team from neurosurgery and neurology treated patients with acute ICH (Q4). The median number of ICH attending physicians was three per hospital (Q5). An ICU (intensive care unit) was the main ward (34.5\%), and a SCU (stroke care unit) was used in only $12.7 \%$ of the respondent hospitals (Q6). The availability of doctors responsible for initial management of emergency ICH patients in the respondent hospitals or on call $24 / 7$ was $61.6 \%(\mathrm{Q} 7)$.

\section{Antihypertensive treatment for acute $\mathrm{ICH}$}

Blood pressure was measured during acute ICH mainly using automated equipment $(81.3 \%$, Q8; Table 2). The median number of BP measurements was 24 during the initial $24 \mathrm{~h}$ (Q9). Two respondents $(0.4 \%)$ replied that AHT should not be performed within $24 \mathrm{~h}$ of ICH onset and the other 548 agreed with AHT (Q10). Thus, we analyzed the following results from these 548 respondents.

Antihypertensive treatment was started mostly in the emergency room or in the CT/MRI room immediately after a diagnosis of $\mathrm{ICH}$ was confirmed $(85.0 \%$, Q11). The threshold median SBP level for AHT initiation was $160 \mathrm{~mm} \mathrm{Hg}$ (interquartile range: (IQR) 150$180 \mathrm{~mm} \mathrm{Hg}$ ), with biphasic peaks at $180 \mathrm{mmHg}(35.6 \%)$ and $160 \mathrm{~mm} \mathrm{Hg}$ (30.8\%, Q12; Figure 1, top). The median levels differed between neurosurgeons (160 mm Hg (IQR: 150-180)) and other physicians $(180 \mathrm{~mm} \mathrm{Hg}(160-180), P<0.001)$. Guideline-based initiation for patients with SBP $\geqslant 180 \mathrm{~mm} \mathrm{Hg}$ was approved by $40.0 \%$ of the overall respondents, $35.3 \%$ of neurosurgeons and $63.0 \%$ of the remainder.

The target of lowering the SBP was also biphasic at $160 \mathrm{~mm} \mathrm{Hg}$ (29.4\%) and $140 \mathrm{~mm} \mathrm{Hg}$ (29.7\%); 448 respondents (81.8\%) approved 140,150 or $160 \mathrm{~mm} \mathrm{Hg}$ as the target (Q13; Figure 1, middle). The median (IQR) target levels of neurosurgeons were $150(140-160)$ $\mathrm{mm} \mathrm{Hg}$ and those of others were $160(150-170) \mathrm{mm} \mathrm{Hg}(P<0.001)$. Intensive lowering to $\leqslant 140 \mathrm{~mm} \mathrm{Hg}$ was approved by $38.1 \%$ of the overall respondents, $41.0 \%$ of neurosurgeons and $23.9 \%$ of the remainder.

The most frequent first choice of i.v. drug was nicardipine (57.1\%), followed by diltiazem (34.9\%, Q14). The main reason for administering nicardipine was its ability to lower BP (96.2\%, Q15). The second choice of respondents (26.5\%) was nicardipine (Q16). Thus, nicardipine was used for acute ICH patients as the first or second choice by $83.5 \%$ of respondents, and by 396 (86.8\%) neurosurgeons 
Table 2 Answers to the web questionnaire

\begin{tabular}{llrr}
\hline \multirow{2}{*}{ Question } & $\begin{array}{l}\text { Multiple choice } \\
\text { answers }\end{array}$ & Respondents $\%$ \\
\hline \multirow{2}{*}{ Q1. Specialty } & Neurosurgery & 457 & 83.1 \\
& Neurology & 63 & 11.5 \\
& Vascular neurology & 12 & 2.2 \\
& Emergency & 2 & 0.4 \\
& Other & 16 & 2.9
\end{tabular}

Q2. Length of career ${ }^{\mathrm{a}}$

$23(18-28)$ years

Q3. Number of $\mathrm{ICH}$ patients

$$
\begin{aligned}
& \leqslant 20 \\
& 21-40 \\
& 41-60 \\
& 61-80 \\
& 81-100 \\
& \geqslant 101
\end{aligned}
$$

Q4. Department for $\mathrm{ICH}$ care

Neurosurgery

(Vascular) Neurology

Mixed team composed of

neurosurgery and

neurology

Emergency

Other

Q5. Number of physicians for acute stroke care ${ }^{a}$

Q6. Ward for $\mathrm{ICH}$ care

Q7. Nighttime/weekend availability of stroke team

$\begin{array}{lrr}\text { Stroke care unit } & 70 & 12.7 \\ \text { Intensive care unit } & 190 & 34.5 \\ \text { Emergency } & 110 & 20.0 \\ \text { General } & 153 & 27.8 \\ \text { Other } & 27 & 4.9 \\ & & \\ \text { Always available in hospital } & 182 & 33.1 \\ & & \\ \text { Always on call } & 157 & 28.5 \\ \text { Occasionally } & 206 & 37.5 \\ \text { Not available } & 5 & 0.9 \\ & & \\ \text { Manual sphygmomanometer } & 71 & 12.9 \\ \text { Automated equipment } & 447 & 81.3 \\ \text { Direct arterial monitor } & 32 & 5.8\end{array}$

Q9. Frequency of BP measurements ${ }^{\mathrm{a}}$

Q10. AHT for acute ICH

$$
\text { Agree }
$$

Disagree

Q11. Timing to initiate AHT

$\begin{array}{lrr}\text { Immediately after diagnosis } & 466 & 85.0 \\ \text { Immediately after admission } & 60 & 10.9 \\ \text { to ward } & & \\ \begin{array}{l}\text { After observation for several } \\ \text { hours }\end{array} & 22 & 4.0\end{array}$

Q12. Threshold SBP to initiate AHT

Q13. Target SBP during hyperacute stage

16.0

21.5

$113 \quad 20.5$

$85 \quad 15.5$

$63 \quad 11.5$

$83 \quad 15.1$

$437 \quad 79.5$

$44 \quad 8.0$

$58 \quad 10.5$

$2 \quad 0.4$

$9 \quad 1.6$

$3(2-5)$

$24(12-48)$

$548 \quad 99.6$

$2 \quad 0.4$

See Figure 1 (middle)
Table 2 Continued

\begin{tabular}{llrr}
\hline \multirow{2}{*}{ Question } & Multiple choice & & \\
& answers & Respondents \% \\
\hline \multirow{2}{*}{ 14. First choice of i.v. drug } & Nicardipine & 313 & 57.1 \\
& Nitroglycerin & 38 & 6.9 \\
& Diltiazem & 191 & 34.9 \\
& Nitroprusside & 0 & 0.0 \\
& Other i.v. drug & 1 & 0.2 \\
& Oral or transdermal drug & 5 & 0.9
\end{tabular}

Q15-1. Reasons for choosing nicardipine in Q14 ${ }^{\mathrm{b}}$

Effectively reduces BP

30196.2

Q16. Second choice of i.v. drug

$$
\text { Safety }
$$

Other

Q15-2. Reasons for choosing nitroglycerin in Q14 ${ }^{\mathrm{b}}$

Effectively reduces BP

Safety

$19 \quad 50.0$

Other

$\begin{array}{ll}28 & 73.7\end{array}$

Q15

Q15-3. Reasons for choice of diltia- Effectively reduces BP zem in Q14 ${ }^{\text {b }}$

$4 \quad 10.5$

$\begin{array}{ll}72 & 37.7\end{array}$

Safety

Others

$\begin{array}{ll}95 & 49.7\end{array}$

$70 \quad 36.6$

Nicardipine

Nitroglycerin

Diltiazem

Nitroprusside

Other i.v. drug

Oral or transdermal drug

$\begin{array}{ll}146 & 26.5\end{array}$

$132 \quad 24.0$

$159 \quad 28.9$

$5 \quad 0.9$

$13 \quad 2.4$

$93 \quad 16.9$

Q17. Inappropriate i.v. drug ${ }^{\mathrm{b}}$

Nicardipine

$141 \quad 25.6$

Nitroglycerin

$123 \quad 22.4$

Diltiazem

$55 \quad 10.0$

Nitroprusside

$83 \quad 15.1$

Any drug is appropriate.

$266 \quad 48.4$

Q18-1. Reasons for choice of nicardipine in Q17

Ineffective BP reduction

0.0

Safety problems

$14 \quad 9.9$

Limitations on official label $\quad 127 \quad 90.1$

Other

$10 \quad 7.1$

Q18-2. Reasons for choice of nitroglycerin in Q17

Ineffective BP reduction

$30 \quad 24.4$

Safety issues

$23 \quad 18.7$

Limitation on official label

Other

$\begin{array}{ll}65 & 52.8\end{array}$

$22 \quad 17.9$

Q18-3. Reasons for choice of diltiazem in Q17 ${ }^{\mathrm{b}}$

Ineffective BP reduction

$16 \quad 29.1$

Safety issues

$19 \quad 34.5$

Limitations on official label $\quad 8 \quad 14.5$

Other

$19 \quad 34.5$

Less BP lowering power

$10 \quad 12.0$ nitroprusside in Q17b $\begin{array}{lll}\text { Safety issues } & 18 \quad 21.7\end{array}$

Limitations on official label $\quad 44 \quad 53.0$

$\begin{array}{lll}\text { Other } & 16 & 19.3\end{array}$ 
Table 2 Continued

\begin{tabular}{|c|c|c|c|}
\hline Question & $\begin{array}{l}\text { Multiple choice } \\
\text { answers }\end{array}$ & Respondents & s \% \\
\hline \multirow{7}{*}{$\begin{array}{l}\text { Q19. Timing of end of } \\
\text { active bleeding }\end{array}$} & $\leqslant 1 \mathrm{~h}$ after $\mathrm{ICH}$ onset & 48 & 8.7 \\
\hline & $1-3 \mathrm{~h}$ & 74 & 13.5 \\
\hline & $3-6 h$ & 156 & 28.4 \\
\hline & $6-12 \mathrm{~h}$ & 121 & 22.0 \\
\hline & $12-24 \mathrm{~h}$ & 90 & 16.4 \\
\hline & $\geqslant 24 h$ & 47 & 8.5 \\
\hline & Other & 14 & 2.5 \\
\hline \multirow[t]{5}{*}{$\begin{array}{l}\text { Q20. First choice of } \\
\text { oral antihypertensive drug }\end{array}$} & $\begin{array}{l}\text { Calcium } \\
\text { channel blocker }\end{array}$ & 360 & 65.5 \\
\hline & ARB & 165 & 30.0 \\
\hline & ACE inhibitor & 25 & 4.5 \\
\hline & $\beta$-Blocker & 0 & 0.0 \\
\hline & Diuretic & 0 & 0.0 \\
\hline
\end{tabular}

Q21. Target SBP during chronic stage
See Figure 1 (bottom)
Abbreviations: $\mathrm{ACE}$, angiotensin-converting enzyme; $\mathrm{AHT}$, antihypertensive therapy; $\mathrm{ARB}$, angiotensin II receptor blocker; BP, blood pressure; ICH, intracerebral hemorrhage; $\mathrm{SBP}$, systolic blood pressure.

aData are expressed as medians (interquartile range).

bultiple answers possible where applicable.

and $63(68.5 \%)$ other respondents $(P=0.14)$. Although $266(48.4 \%)$ respondents answered that any i.v. drugs that lower BP are appropriate for patients with acute $\mathrm{ICH}, 141(25.6 \%)$ replied that nicardipine is inappropriate, mainly because of the contraindications described on the label (90.1\%, Q17, Q18). Around half of the respondents replied that active intracranial bleeding ceases within $6 \mathrm{~h}(50.5 \%$, Q19).

After i.v. AHT, 360 respondents (65.5\%) administer oral AHT using a calcium channel blocker, followed by an angiotensin II receptor blocker (30.0\%, Q20). The target SBP value of 333 respondents $(60.5 \%)$ was $\leqslant 140 \mathrm{~mm} \mathrm{Hg}(\mathrm{Q} 21)$. The median (IQR) target values of neurosurgeons were $140(140-140) \mathrm{mm} \mathrm{Hg}$ and those of other physicians were $140(130-140) \mathrm{mm} \mathrm{Hg}(P=0.001)$.

\section{Supplementary inquiry}

Among the respondents to the initial web questionnaire, 414 (75.3\%) expressed an interest in further inquiries. We sent them another questionnaire to determine whether their patients experienced any possible side effects of i.v. antihypertensive drugs. A total of 32 physicians responded. Of them, 18 had patients who experienced bradycardia or atrioventricular block and one had a patient who developed arrhythmia during diltiazem administration. Nicardipine caused phlebitis $(n=6)$, tachycardia $(n=3)$ and liver dysfunction $(n=2)$. One respondent described a decrease of oxygen partial pressure in arterial blood in a patient receiving nitroglycerin. A total of 10 respondents replied that i.v. drug administration did not cause side effects.

\section{DISCUSSION}

This study shows the current strategies regarding AHT for acute $\mathrm{ICH}$ patients in Japan. The first major finding was that $60 \%$ of the respondents start AHT on the basis of a threshold SBP level that is lower than that recommended by guidelines $(180 \mathrm{~mm} \mathrm{Hg})$. The second major finding was that $80 \%$ of the respondents lowered SBP


Figure 1 Answers to Questions 12, 13 and 21. Top: Threshold systolic blood pressure (SBP) required to start antihypertensive treatment (AHT). Middle: SBP during hyperacute stage by intravenous AHT. Bottom: SBP during chronic stage targeted by oral AHT. DBP: diastolic blood pressure ( $\mathrm{mm} \mathrm{Hg}$ ) used by respondents rather than SBP as threshold or target value.

to a maximum of 140,150 or $160 \mathrm{~mm} \mathrm{Hg}$, and $40 \%$ intensively lowered SBP to $\leqslant 140 \mathrm{~mm} \mathrm{Hg}$. These two findings mainly reflect the opinions of neurosurgeons, as they accounted for $80 \%$ of the respondents. Both the threshold SBP level required to initiate AHT and the target SBP level were higher according to responses from other physicians (mainly neurologists and vascular neurologists) compared with those from neurosurgeons. The third major finding was that nicardipine is the most effective i.v. drug to reduce BP of patients with acute $\mathrm{ICH}$, although such usage conflicts with the official Japanese label.

The threshold SBP level required to initiate AHT and the target SBP level recommended in the guidelines are not identical and are not based on sophisticated trials; over half of the respondents set lower values for these two parameters than those recommended by the AHA/ASA guidelines. The present findings indicate that most Japanese neurosurgeons prefer stricter AHT for ICH patients than that 
recommended by the current guidelines. This tendency might be because a stricter AHT than the usual one is recommended when surgical therapy is scheduled for ICH in Japanese guidelines, although the evidence level is not high. ${ }^{20} \mathrm{~A}$ lower target SBP than the guidelines recommend has been reported recently. Ohwaki et al. ${ }^{20}$ assessed 76 patients with ICH and found that an SBP target of $\leqslant 150 \mathrm{~mm} \mathrm{Hg}$ was less significantly associated with hematoma growth than that of $\geqslant 160 \mathrm{~mm} \mathrm{Hg}$. Our observational study of 244 patients with ICH showed that lowering SBP to $<138 \mathrm{~mm} \mathrm{Hg}$ during the initial $24 \mathrm{~h}$ after admission seems to predict a favorable early outcome. ${ }^{21}$ Two major clinical trials are ongoing to determine the safety and efficacy of intensively lowering BP for acute ICH: the Intensive Blood Pressure Reduction in Acute Cerebral Hemorrhage Trial (INTERACT) ${ }^{22}$ and the Antihypertensive Treatment of Acute Cerebral Hemorrhage $(\mathrm{ATACH}) .{ }^{23}$ The vanguard phase of INTERACT showed that early intensive lowering of BP with a targeted SBP of $140 \mathrm{~mm} \mathrm{Hg}$ and careful monitoring was feasible, safe and might have modestly attenuated hematoma growth in 346 randomized patients in the standard best practice stroke unit care. ${ }^{22}$ Phase I of ATACH investigated the potential consequences of controlling BP with i.v. nicardipine at the sequential levels of 170-200, 140-170 and 110$140 \mathrm{mmHg}$ in 60 patients. $^{23}$ The result was announced in a recent conference. $^{22}$

This survey clarified a contradiction regarding the prevalence of nicardipine administration to Japanese patients with ICH regardless of the following contraindications described on the official label; 'nicardipine is contraindicated for (I) ICH patients with a suspicion of ongoing intracranial bleeding not to enhance bleeding and for (II) acute stroke patients with elevated intracranial pressure not to accelerate intracranial pressure elevation.' When nicardipine was originally approved for commercial use as an ameliorant of cerebral circulation, not as an antihypertensive agent, in Japan in 1981, a description of the above contraindications was listed on the label following that of another ameliorant of cerebral circulation. As far as we can determine, the limited administration of nicardipine for patients with ongoing intracranial bleeding or high intracranial pressure is not supported by any scientific evidence. The description on the label has another problem in that the time when active intracranial bleeding ceases is not as clear as stated in the answer to Q19. On the basis of the results of this survey, a formal request for reassessment of the official label of nicardipine was submitted to the Ministry of Health, Labour and Welfare of Japan by the Japan Stroke Society, Japan Neurosurgical Society and the Japanese Society of Hypertension in October 2008. Diltiazem was the second most frequently administered drug, which seems to be associated with an influence on cardiac rhythms. On the basis of Japanese official labels, nitroglycerin is not administered to lower BP except for patients with acute heart failure, unstable angina or perioperative conditions, and nitroprusside is limited to patients with severely damaged cerebral circulation. A limitation of this study was that we did not ask in the web questionnaires whether respondents know the contraindication of nicardipine listed on the official label. It is important to know how many doctors use nicardipine with or without knowing this contraindication.

Calcium channel blockers and angiotensin II receptor blockers were the choices of oral antihypertensive drugs after i.v. administration in 65.5 and $30.0 \%$ of respondents, respectively. The most frequent target SBP according to our respondents $(140 \mathrm{~mm} \mathrm{Hg})$ was identical to the level recommended by the guidelines of the Japanese Society of Hypertension $^{23}$ and higher than that in the guidelines from the European Society of Hypertension and European Society of Cardio$\operatorname{logy}(130 \mathrm{~mm} \mathrm{Hg}){ }^{24}$
In conclusion, current Japanese strategies based on this survey regarding acute BP lowering for ICH patients, especially by neurosurgeons, differ considerably from strategies recommended in various guidelines. We are planning to conduct a multicenter, randomized clinical trial of Japanese patients with $\mathrm{ICH}$ to determine the optimal BP target of AHT based on the results of this survey.

\section{CONFLICT OF INTEREST}

The authors declare no conflict of interest.

\section{ACKNOWLEDGEMENTS}

This study was supported in part by Grants-in-Aid (H20-Junkanki-Ippan-019, chief investigator: Kazunori Toyoda, MD) from the Ministry of Health, Labour and Welfare of Japan.

1 Broderick JP, Brott T, Tomsick T, Huster G, Miller R. The risk of subarachnoid and intracerebral hemorrhages in blacks as compared with whites. N Engl J Med 1992; 326: 733-736

2 Furlan AJ, Whisnant JP, Elveback LR. The decreasing incidence of primary intracerebral hemorrhage: a population study. Ann Neurol 1979; 5: 367-373.

3 Drury I, Whisnant JP, Garraway WM. Primary intracerebral hemorrhage: impact of CT on incidence. Neurology 1984; 34: 653-657.

4 Brott T, Thalinger K, Hertzberg V. Hypertension as a risk factor for spontaneous intracerebral hemorrhage. Stroke 1986; 17: 1078-1083.

5 Schutz H, Bodeker RH, Damian M, Krack P, Dorndorf W. Age-related spontaneous intracerebral hematoma in a German community. Stroke 1990; 21: 1412-1418.

6 Mohr JP, Caplan LR, Melski JW, Goldstein RJ, Duncan GW, Kistler JP, Pessin MS, Bleich HL. The Harvard Cooperative Stroke Registry: a prospective registry. Neurology 1978; 28: 754-762.

7 Qureshi AI, Suri MA, Safdar K, Ottenlips JR, Janssen RS, Frankel MR. Intracerebral hemorrhage in blacks. Risk factors, subtypes, and outcome. Stroke 1997; 28: 961-964.

8 Carlberg B, Asplund K, Hagg E. The prognostic value of admission blood pressure in patients with acute stroke. Stroke 1993; 24: 1372-1375.

9 Britton M, Carlsson A, de Faire U. Blood pressure course in patients with acute stroke and matched controls. Stroke 1986; 17: 861-864.

10 Fogelholm R, Avikainen S, Murros K. Prognostic value and determinants of first-day mean arterial pressure in spontaneous supratentorial intracerebral hemorrhage. Stroke 1997; 28: 1396-1400.

11 Terayama Y, Tanahashi N, Fukuuchi Y, Gotoh F. Prognostic value of admission blood pressure in patients with intracerebral hemorrhage. Keio Cooperative Stroke Study. Stroke 1997; 28: 1185-1188.

12 Kazui S, Minematsu K, Yamamoto H, Sawada T, Yamaguchi T. Predisposing factors to enlargement of spontaneous intracerebral hematoma. Stroke 1997: 28: 2370-2375.

13 Kuwata N, Kuroda K, Funayama M, Sato N, Kubo N, Ogawa A. Dysautoregulation in patients with hypertensive intracerebral hemorrhage. A SPECT study. Neurosurg Rev 1995; 18: 237-245.

14 Qureshi Al, Bliwise DL, Bliwise NG, Akbar MS, Uzen G, Frankel MR. Rate of 24-h blood pressure decline and mortality after spontaneous intracerebral hemorrhage: a retrospective analysis with a random effects regression model. Crit Care Med 1999; 27: 480-485.

15 Qureshi AI, Wilson DA, Hanley DF, Traystman RJ. Pharmacologic reduction of mean arterial pressure does not adversely affect regional cerebral blood flow and intracranial pressure in experimental intracerebral hemorrhage. Crit Care Med 1999; 27: 965-971.

16 Powers WJ, Zazulia AR, Videen TO, Adams RE, Yundt KD, Aiyagari V, Grubb Jr RL, Diringer MN. Autoregulation of cerebral blood flow surrounding acute $(6-22 \mathrm{~h})$ intracerebral hemorrhage. Neurology 2001; 57: 18-24.

17 Broderick J, Connolly S, Feldmann E, Hanley D, Kase C, Krieger D, Mayberg M, Morgenstern L, Ogilvy CS, Vespa P, Zuccarello M. Guidelines for the management of spontaneous intracerebral hemorrhage in adults: 2007 update: a guideline from the American Heart Association/American Stroke Association Stroke Council, High Blood Pressure Research Council, and the Quality of Care and Outcomes in Research Interdisciplinary Working Group. Stroke 2007; 38: 2001-2023.

18 Shinohara Y, Yamaguchi T. Outline of the Japanese Guidelines for the Management of Stroke 2004 and subsequent revision. Int J Stroke 2008; 3: 55-62.

19 Steiner T, Kaste M, Forsting M, Mendelow D, Kwiecinski H, Szikora I, Juvela S, Marchel A, Chapot R, Cognard C, Unterberg A, Hacke W. Recommendations for the management of intracranial haemorrhage_-part I: spontaneous intracerebral haemorrhage. The European Stroke Initiative Writing Committee and the Writing Committee for the EUSI Executive Committee. Cerebrovasc Dis 2006; 22: 294-316.

20 Ohwaki K, Yano E, Nagashima H, Hirata M, Nakagomi T, Tamura A. Blood pressure management in acute intracerebral hemorrhage: relationship between elevated blood pressure and hematoma enlargement. Stroke 2004; 35: 1364-1367. 
21 Itabashi R, Toyoda K, Yasaka M, Kuwashiro T, Nakagaki H, Miyashita F, Okada Y, Naritomi $\mathrm{H}$, Minematsu K. The impact of hyperacute blood pressure lowering on the early clinical outcome following intracerebral hemorrhage. J Hypertens 2008; 26: 2016-2021.

22 Qureshi AI, Qureshi Z, Palesch YY. Antihypertensive Treatment of Acute Cerebral Hemorrhage (ATACH) trial: final results. Stroke 2009; 40: e111 (abstract).

23 Ogihara T, Kikuchi K, Matsuoka H, Fujita T, Higaki J, Horiuchi M, Imai Y, Imaizumi T, Ito S, Iwao H, Kario K, Kawano Y, Kim-Mitsuyama S, Kimura G, Matsubara H, Matsuura H, Naruse M, Saito I, Shimada K, Shimamoto K, Suzuki H, Takishita S, Tanahashi N, Tsuchihashi T, Uchiyama M, Ueda S, Ueshima H, Umemura S, Ishimitsu T, Rakugi H, on behalf of The Japanese Society of Hypertension Committee. The Japanese Society of Hypertension Guidelines for the Management of Hypertension (JSH 2009). Hypertens Res 2009; 32: 3-107.
24 Mancia G, De Backer G, Dominiczak A, Cifkova R, Fagard R, Germano G, Grassi G, Heagerty AM, Kjeldsen SE, Laurent S, Narkiewicz K, Ruilope L, Rynkiewicz A, Schmieder RE, Boudier HA, Zanchetti A, Vahanian A, Camm J, De Caterina R, Dean V, Dickstein K, Filippatos G, Funck-Brentano C, Hellemans I, Kristensen SD, McGregor K, Sechtem U, Silber S, Tendera M, Widimsky P, Zamorano JL, Erdine S, Kiowski W, Agabiti-Rosei E, Ambrosioni E, Lindholm LH, Viigimaa M, Adamopoulos S, Bertomeu V, Clement D, Farsang C, Gaita D, Lip G, Mallion JM, Manolis AJ, Nilsson PM, O'Brien E, Ponikowski P, Redon J, Ruschitzka F, Tamargo J, van Zwieten P, Waeber B, Williams B. 2007 Guidelines for the Management of Arterial Hypertension: the task force for the management of arterial hypertension of the European Society of Hypertension (ESH) and of the European Society of Cardiology (ESC). J Hypertens 2007; 25: 1105-1187. 